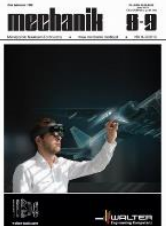

\title{
Correction of machining deviations of 2D profiles described with NURBS curves
}

\author{
Korekcja odchyłek obróbkowych profili 2D opisanych krzywymi NURBS
}

\section{ANDRZEJ WERNER*}

The method of correction of machining of curvilinear profiles is presented. This method is based on the use of coordinate measurements of the pre-manufactured object. The results of the measurements contain information about the observed machining deviations. These data are used in the reconstruction of the geometric model of the produced profile.

KEYWORDS: curvilinear profile, CNC milling machine, coordinate measurements, correction of deviations

Precise manufacture of objects containing curvilinear geometrical elements is often indispensable in the production of tooling and tools (sheet blanks, electrodes for EDM machining, die for injection molds). Maintaining proper manufacturing accuracy requires the use of procedures to compensate for machining errors.

There are many ways of such compensation. One of them is to determine the geometrical errors of the CNC machine tool [1] and to use them for the correction of machining programs [2]. Another approach is the analysis of errors, the source of which is the machining process and the accompanying phenomena [3]. Adaptive control systems are being developed, correcting the position of the tool in real time [4].

Another universal method of increasing the accuracy of the production of elements uses coordinate measurements. The correction of the machining process is based on the results of measurements made on a CNC machine $[5,6]$ or on a coordinate measuring machine [7]. Measurement data obtained in two ways are most often compared to nominal CAD models of workpieces. On this basis, machining deviations, used to correct production errors, are determined.

The method of increasing accuracy proposed in the article is based on measurements performed on a coordinate measuring machine. Correction of machining programs is carried out indirectly by converting the nominal CAD model of the object into a corrected geometric model, taking into account the deviations observed after the initial machining of the object.

\footnotetext{
* Dr inż. Andrzej Werner (a.werner@pb.edu.pl) - Katedra Inżynierii Materiałowej i Produkcji, Wydział Mechaniczny Politechniki Białostockiej
}

\section{Method of increasing the accuracy of producing a curvilinear profile}

The method proposed in the article is implemented in the following stages:

- construction of a nominal geometric profile model,

- creating machining programs of the manufactured object and pre-machining on a CNC milling machine,

- coordinate measurements of the object, determination from bends and their components,

- determination of coordinates of the corrected profile at measuring points,

- reconstruction of the geometrical model of the produced profile, creation of corrected machining programs and machining of the object,

- coordinate measurements and assessment of the improvement in the accuracy of the curvilinear profile production.

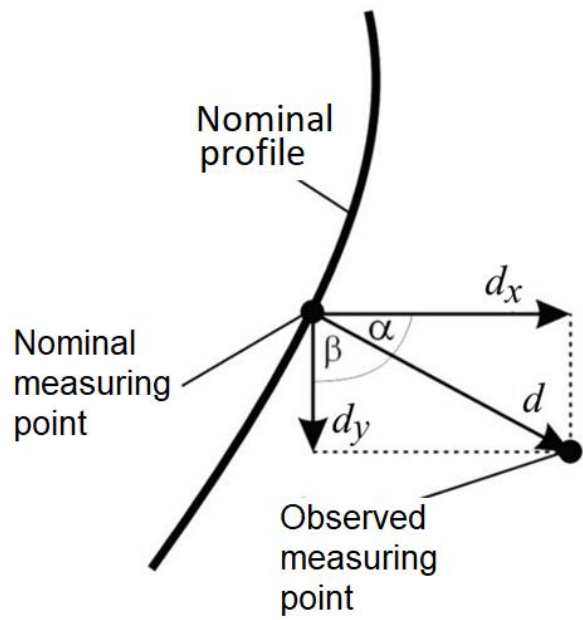

Fig. 1. Graphical representation of machining deviation

The basic element of the proposed method is the process of rebuilding the geometric model of the object being manufactured. It begins with coordinate control measurements of the pre-machined profile. The measurement results contain information about the observed machining deviations. The measure of the determined deviations are the distances between points on the profile (the CAD nominal model) and the corresponding points observed as a result of the 
measurements. Deviations are determined in the normal direction to the profile being processed (fig. 1).

After the coordinate measurements have been made, information on the coordinates of nominal points and observed machining deviations as well as directiona cosines at the measuring points is available. Based on this information, you can start the correction of the curvilinear profile describing the object being manufactured.

First of all, the components of machining deviations are determined. The dependencies are used for calculations:

$$
d_{x i}=d_{i} \cdot \cos \alpha_{i} \quad d_{y i}=d_{i} \cdot \cos \beta_{\mathrm{i}}
$$

where: $d_{x i}, d_{y i}$ - components of observed machining deviations; $d_{i}$ - deviation observed at the measurement point, $\cos \alpha_{i}, \cos \beta_{i}$ - directional cosines at measurement points, $i$-measurement point number.

Calculated components of machining deviations allow the calculation of the corrected coordinates of points. If the correction is carried out on the "raw" measurement data, the coordinates corrected at the measuring points will be determined from the dependence:

$$
x_{i}^{\text {cor }}=x_{i}^{\text {nom }}-d_{x i} \quad y_{i}^{\text {cor }}=y_{i}^{\text {nom }}-d_{y i}
$$

where: $x_{i}^{\text {cor }}, y_{i}^{\text {cor }}$ - corrected coordinates of the curvilinear profile, $x_{i}^{\text {nom }}, y_{i}^{\text {nom }}$ - coordinates of points on the nominal profile (CAD model).

This approach is the simplest, but it does not guarantee the best effect. Due to the complexity of the machining and measurement process, observed deviations may contain significant effects of random phenomena. These deviations have two components: determined and random. The introduction of the measurement data filtration makes it possible to minimize the influence of random deviations on the effect of machining deviations correction. Formula (1) changes the form and the composition of the corrected deviation is determined from the relationship:

$$
d_{x i}=d_{i}^{f} \cdot \cos \alpha_{i} \quad d_{y i}=d_{i}^{f} \cdot \cos \beta_{i}
$$

where: $d_{i}^{f}$ - filtered components of observed machining deviations.

The methods of data filtration are many. The key to choosing the right method should be its simplicity. The next part of the article will present an approach taken from the time series analysis techniques.

As a result of the procedure carried out, a set of corrected points is obtained. In the CAD system, the curve is inter-curved by them. In this way, a geometric model of the produced profile is compensated for the observed machining deviations.

\section{Experimental verification of methods of increasing accuracy}

The method proposed in the article has been verified on the example of the curvilinear profile described in the NURBS curve (fig. 2). The curve was built on a control polygon consisting of 15 vertices. Degree of $B$-spline base functions $n=3$.

The construction of the CAD model of the facility and the preparation of programs controlling the machining were carried out in the MasterCAM system. The finishing treatment was carried out with a face mill with a diameter of $10 \mathrm{~mm}$. The machining parameters adopted are: feed 300 $\mathrm{mm} / \mathrm{min}$, spindle work $6000 \mathrm{rpm}$, allowance $0.3 \mathrm{~mm}$. The object was made of aluminum alloy PA6 (fig. 3 ).

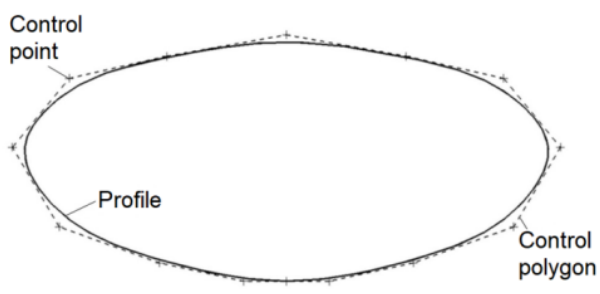

Fig. 2. Curvilinear profile produced

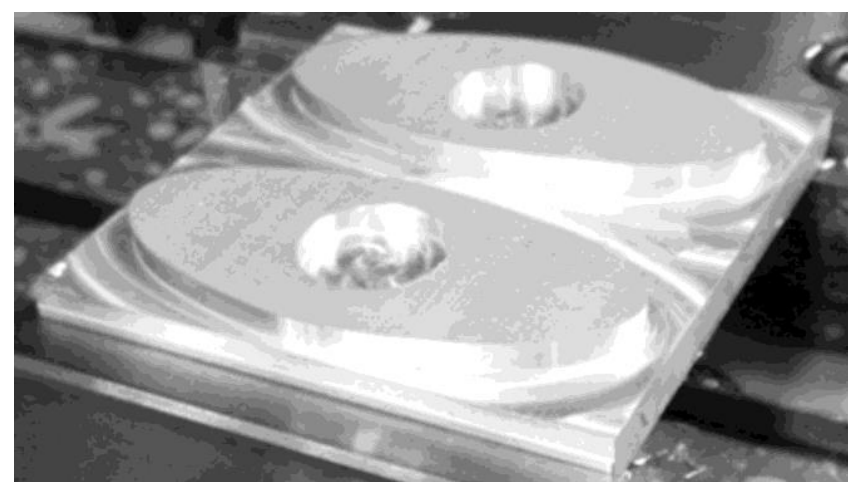

Fig. 3. Created curvilinear profile

At the end of the production phase, the test object was subjected to control measurements on a Hexagon Metrology Global Performance machine (PC-DMIS software, MPEE = $1.5+\mathrm{L} / 333 \mu \mathrm{m}$, Renishaw SP25M measuring head, $20 \mathrm{~mm}$ spherical styli) with a diameter of $\varnothing 2 \mathrm{~mm}$ ). The measurements used one of the automatic scanning procedures available in the PC-DMIS system. 200 measurement points were obtained, the distribution of which is shown in fig. 4 .

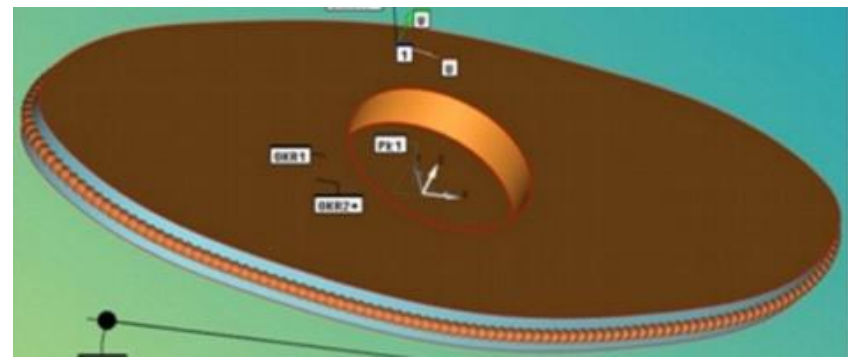

Fig. 4. Distribution of measurement points

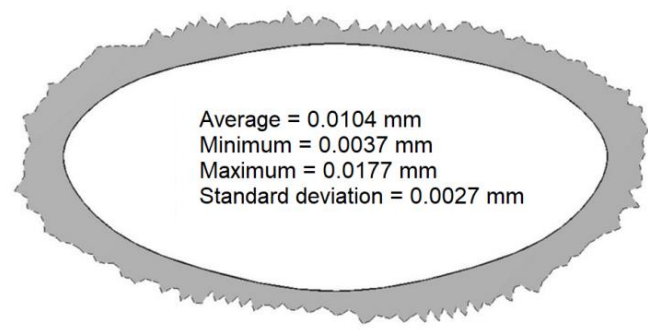

Fig. 5. Distribution of deviations and a set of results of coordinated measurements

As a result of the measurements carried out, information on 200 observed deviations was obtained. The distribution of deviations (in the 500:1 scale) and the results are shown in fig. 5. All deviations ranged from $0.003 \div 0.017 \mathrm{~mm}$.

- Filtration of measurement data. It was proposed to adapt the filter based on the weighted moving average. It is popular in the processing of time series.

The use of this filter in the processing of measurement data means that the values of points from its environment are taken into account in calculating the new point value. Each measuring point from the environment contributes its 
contribution - weight - to the calculation. These weights are saved in the form of a mask. Typical mask sizes are 3, 5 or 7 .

The principle of data filtration based on the filter with mask 5:

\begin{tabular}{|c|c|c|c|c|}
\hline$f_{\mathrm{i}-2}$ & $f_{\mathrm{i}-1}$ & $f_{\mathrm{i}}$ & $f_{\mathrm{i}+1}$ & $f_{\mathrm{i}+2}$ \\
\hline
\end{tabular}

The deviations observed at the measuring points take the form of a series consisting of $n$ elements. The new value of the di-point component is calculated in two steps. First, the weighted sum of the point component and all neighbors is calculated according to the weights indicated by the filter mask.

$$
d_{i}^{\prime}=f_{i-2} * d_{i-2}+f_{i-1} * d_{i-1}+f_{i} * d_{i}+f_{i+1} * d_{i+1}+f_{i+2} * d_{i+2}
$$

The amount thus obtained is divided by the sum of all the mask weights, if it is different from 0 . In this way, a filtered component of the observed machining error is obtained.

$$
d_{i}^{f}=\frac{d_{i}^{\prime}}{f_{i-2}+f_{i-1}+f_{i}+f_{i+1}+f_{i+2}}
$$

Normalization of the component value of the observed machining error results in a smoother decomposition of deviations and minimizes the influence of random components on the result of machining error correction.

The mask 5 was used to test the proposed procedure. Due to the even distribution of the measurement points, it was assumed that the influence of all points surrounding the deviation being processed is the same (all weights equal to 1). The data filtration effect for the first 100 measurement points is shown in fig. 6 .

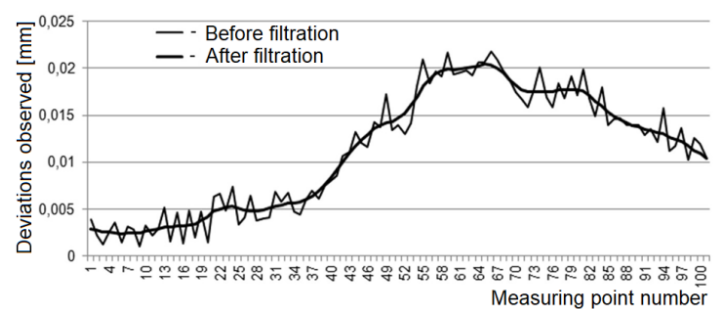

Fig. 6. Result of filtration of measurement data

Comparing the distribution of deviations before and after filtration, one can notice a significant smoothing of the profile representing individual levels of deviations. This is due to the reduced impact of random components generated during the machining and measurement process.

- Improvement in the accuracy of producing a crosssection profile. According to the described procedure, two corrected geometric models of the produced profile were started. The first model was reconstructed on the basis of "raw" coordinate measurements. In the second case, filtered deviations were used to rebuild the model.

At the initial stage of the correction process, the nominal coordinates and coordinates of 200 measurement points were separated from the measurement program.
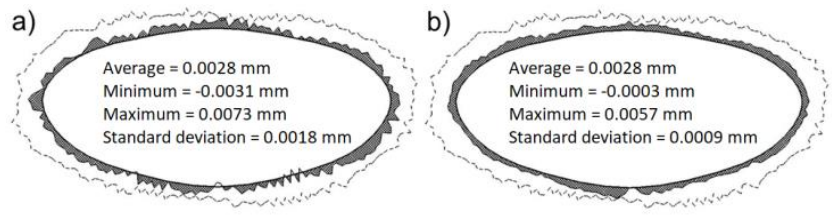

Fig. 7. Results of machining deviations correction: a) on "raw" measurement data, b) on filtered machining data

Using the equations (1), (2) and (3), two sets of coordinate corrected have been determined (before and after filtration of measurement data). Based on them, two corrected curves were created in the Mastercam system describing the produced profile.
Based on the rebuilt models of geometric parts, machining programs were re-created. The same tools and parameters used in the initial machining of the object were used. The re-created two curvilinear profiles were subjected to coordinate measurements.

Distributions of obtained machining deviations are shown in fig. 7. The outer contour shows the distribution of deviations after pre-treatment (before correction).

\section{TABLE. List of results of machining deviations correction}

\begin{tabular}{|l|c|c|c|}
\hline \multicolumn{1}{|c|}{$\mathrm{mm}$} & Before correction & $\begin{array}{c}\text { After correction } \\
- \text { "raw" data }\end{array}$ & $\begin{array}{c}\text { After correction - } \\
\text { data after filtration }\end{array}$ \\
\hline Average & +0.0104 & +0.0028 & +0.0028 \\
\hline Min./max. & $+0.003 /+0.017$ & $-0.003 /+0.007$ & $0.000 /+0.0057$ \\
\hline $\begin{array}{l}\text { Height of the } \\
\text { profile }\end{array}$ & 0.0140 & 0.0104 & 0.0060 \\
\hline $\begin{array}{l}\text { Standard } \\
\text { deviation }\end{array}$ & 0.0027 & 0.0018 & 0.0009 \\
\hline
\end{tabular}

The table contains numerical values illustrating the effect of the correction of machining deviations. In both cases, a significant improvement in production accuracy was achieved.

\section{Conclusions}

The use of the presented method has made it possible to significantly increase the accuracy of the curvilinear profile production. The table presents the results observed before and after the correction using two methods. In both cases, they prove the effectiveness of the proposed procedure.

The results show a clear decrease in observed machining deviations. The introduction of filtration of measurement data made it possible to obtain the best final result. Observed deviations and profile height are the smallest in this case. Standard deviation values and their average indicate an additional, positive effect of smoothing the obtained profile.

The curvilinear profile produced shows the greatest similarity to the nominal CAD model. The filtration of the measured data made it possible to reduce the influence of random components of the observed machining deviations on the process of increasing the accuracy of production.

\section{REFERENCES}

1. Wenjie T., Weiguo G., Dawei Z., Tian H. "A general approach for error modeling of machine tools". International Journal of Machine Tools \& Manufacture. 79 (2014): pp. 17-23.

2. Mehrdad V.N., Nojedeh M.H., Behrooz A. "Tool path accuracy enhancement through geometrical error compensation". International Journal of Machine Tools \& Manufacture. 51 (2011): pp. 471-482.

3. Hansel A., Yamazaki K., Konishi K. "Improving CNC machine tool geometric precision using manufacturing process analysis techniques". Procedia CIRP. 14 (2014): pp. 263-268.

4. Mohsen H., Behrooz A., Mehrdad V.N. "Tool deflection and geometrical error compensation by tool path modification". International Journal of Machine Tools \& Manufacture. 51 (2011): pp. 439-449.

5. Cho M.W., Seo T.I., Kwon H.D. "Integrated error compensation method using OMM system for profile milling operations". Journal of Materials Processing Technology. 136 (2003): pp. 88-99.

6. Chen Y., Gao J., Deng H., Zheng D., Chena X., Kelly R. "Spatial statistical analysis and compensation of machining errors for complex surfaces". Precision Engineering. 37 (2013): pp. 203-212.

7. Poniatowska M., Werner A. "Fitting spatial models of geometric deviations of free-form surfaces determined in coordinate measurements". Metrology and Measurement Systems. 17, 4 (2010): pp. 599-610.

Translation of scientific articles, their computer composition and publishing them on the website www.mechanik.media.pl by original articles in Polish is a task financed from the funds of the Ministry of Science and Higher Education designated for dissemination of science. 